\title{
MI RELACIÓN CON EL DR. LUIS CIFUENTES DELATTE
}

\author{
Carlos Guitián Rodríguez
}

Servicio de Urología. (Uubilado). Hospital Provincial de Ourense. Ourense. España.

Resumen.- En este artículo el autor quiere expresar su admiración y agradecimiento a su maestro en cirugía urológica endoscópica, y muestra sus inicios en la práctica de esta técnica y los éxitos alcanzados gracias a las enseñanzas del Dr. Cifuentes.

Palabras clave: Resección. Hemolisis. Correspondencia. Película. Luis Cifuentes Delatte.
Summary.- In this article the author wants to express his admiration and thankfulness to his Professor in urological endoscopic surgery and show his start in the practice of such technique, and the success achieved thanks to the teachings of Dr. Cifuentes.

Keywords: Transurethral resection of the prostate. Haemolysis. Mail. Movie. Dr. Luis Cifuentes Delatte.

\section{INTRODUCCIÓN}

Fui invitado por el Dr. Pérez Castro Ellendt, director de Archivos Españoles de Urología, para colaborar en un número monográfico dedicado al admirado maestro, Don Luis Cifuentes Delatte, cosa que hago con el mayor de mis deseos. Para mí, don Luis, no sólo fue mi maestro, sino también mi amigo.

Estoy escribiendo estas líneas en un ambiente que era propicio para don Luis, ya que estoy escuchando música clásica de la que el maestro era gran aficionado y tarareaba frecuentemente. A mi lado tengo una fotografía suya de medio cuerpo, vestido impecablemente con traje gris y chaleco y con las manos en los bolsillos del pantalón. Pero lo que más llama la atención, es su cara con una ligera sonrisa bondadosa como era él. En la dedicatoria que me hizo el 24 de noviembre de 1965, dice: "Para el Dr. Carlos Guitián, muy afectuosamente, su amigo, Luis Cifuentes Delatte".

Obtenida la especialidad de Urología en Barcelona, establecí mi consulta privada en mi ciudad natal, Ourense, en 1959, con el título de especialidad dado por el catedrático de la Facultad de Medicina de Madrid, Don Alfonso De La Peña. Mi 
padre era especialista en Dermatología y Venereología en el antiguo Hospital Provincial de la Diputación de Ourense, llamado Hospital Modelo; por aquellos tiempos su especialidad era la predecesora de la Urología, en su época había frecuentes estenosis uretrales debido a la blenorragia. Tenía una colección completa de beniqués de acero, que usé yo algunas veces, sondas y dilatadores uretrales de diversos tipos, uretroscopio, uretrotomos, así como libros en castellano (Reynaldo Dos Santos, Guyón, etc.) y varios franceses que eran verdaderos tratados de Urología. Como no existía la especialidad de urología en el Hospital, me hice cargo de estos pacientes.

Eran tiempos de escasez, de pobreza y de emigración cuando yo empecé a ejercer. Casi todos los pacientes que llegaban al hospital, además de ser pobres, gran parte de ellos, eran campesinos, residían en aldeas, y tardaban en llegar a veces uno o dos días. Abundaba la tuberculosis y la renal como una de sus manifestaciones, las pionefrosis, abscesos renales, cálculos urinarios, retenciones de orina, etc. Realicé múltiples nefrectomías, operaciones de próstata benignas, pielo y ureterostomías por cálculos y patologías que actualmente son difíciles de encontrar como la rotura de uretra prostática en un paciente con retención de orina de tres días de una lejana aldea que intentó "desatascarse" con un palo, un empalamiento sobre el "estadullo" de un carro de bueyes, desde el periné hasta la zona precordial izquierda afectando a base y cúpula vesical, dos casos de implantación de uréteres en sigma por extrofia vesical, hipotalias, etc.

Creía que mi formación urológica era completa por la práctica adquirida en el Hospital, de Ourense hasta que en 1962 adquirí un libro escrito por Luís Cifuentes Delatte titulado "Cirugía Urológica Endoscópica" (primera edición, 1962) que para mí fue una novedad y no solo me sorprendió, sino que me entusiasmó. Yo desconocía esa técnica al igual que le sucedería a la mayor parte de los urólogos españoles- y pensé que con ella la Urología daba un gran paso y que esa técnica tenía que imponerse, ya que era muy beneficiosa para los pacientes. El libro lo consideré magnífico, muy didáctico, escrito con un lenguaje sencillo, como emplean los buenos escritores, con una detallada descripción, acompañada de fotografías de diverso material y excelentes dibujos endoscópicos. Lo leí con gran interés y fue tal mi entusiasmo por esa nueva técnica quirúrgica que me desplacé a Madrid con la esperanza de que el Dr. Cifuentes me aceptase en su Servicio durante una temporada.

En Madrid me dirigí al Gran Hospital General de la Beneficiencia, que estaba en obras y no me caí por el hueco del ascensor de verdadero milagro. Me presenté al Dr. Cifuentes, (allí le llamaban D. Luís) y le dije que había leído su libro que me sorprendió ya que para mí era una novedad, que era un urólogo con buena práctica quirúrgica en cirugía abierta ya que llevaba dos años ejerciendo como urólogo en el Hospital Provincial de Ourense, pero en lo concerniente a la cirugía endoscópica, sólo empleaba el cistoscopio y a veces hacía electrocoagulaciones de pequeños papilomas vesicales. Me contestó diciendo que no tendría inconveniente en aceptarme como observador y me advirtió que la técnica endoscópica era más difícil de aprender que la cirugía abierta ya que no se veía como sucede en la cirugía abierta y que hay que tener paciencia y perseverancia y sobre todo aptitudes. La comparó a una escultura. Al decirle yo que era aficionado a la escultura quedó un poco pensativo, y con los dedos en la barbilla me dijo que entonces tendría más facilidad para el aprendizaje, que podía asistir a sus sesiones endoscópicas, y si mostraba gran interés y encima era escultor, esperaba que fuese un buen reseccionista. Quien me iba a decir a mí que unos años después en la segunda edición de la Cirugía Urológica Endoscopia, revisada y aumentada me citaría $D$. Luís en la bibliografía del capítulo correspondiente a la R.T. (así escribía D. Luís) de la neoplasias vesicales por un trabajo que publiqué en Archivos Españoles de Urología (1976), titulado "La R.T.U. en los grandes tumores vesicales benignos".

Salí muy contento de la entrevista con D. Luís, no sólo por haberme admitido en su servicio sino que también porque vi en él una humanidad y un trato caballeresco poco frecuente. Me incorporé a su servicio hospitalario y comencé a asistir a las sesiones clínicas preoperatorios con sus colaboradores mediante lectura del historial clínico y exposición de urografías y si se trataba de un prostático, cistografía lacunar (desconocida para mí). Los casos de cirugía abierta los solían hacer sus colaboradores y la cirugía endoscópica generalmente la hacía D. Luís. Yo me situaba detrás de él y observaba los mínimos detalles: como era el tipo de resector (aparato nuevo para mí) modelo NESBIT de luz convencional y pequeñas lamparitas en su extremo, que a veces se fundían; los diferentes calibres de las vainas y su correspondiente obturador, la fuente de luz (cuatro pilas de linterna) que colgaba de la mesa operatoria, los aspiradores Ellik, colocación de los pedales de corte y coagulación y altura de los envases de vidrio en los que vertía agua estéril su ayudante (Gonzalo), la introducción del resectoscopio, al que conectaba el tubo de lavado en la llave de paso que regulaba por medio del dedo índice de la mano izquierda durante la intervención, los lavados y aspiración de los trozos resecados mediante el aspirador de Ellik, como manejaba el resectoscopio 
en los distintos momentos y al final cuando el agua de lavado era casi clara, lavado vesical y recogida de los trozos para pesaje y análisis histopatológico. Esta observación la hacía todos los días, y viendo D. Luís mi interés y constancia me daba explicaciones del momento de la resección y ponía la óptica de enseñanza pero era engorrosa y disminuía el campo de visión, como pude observar más adelante en mi servicio hospitalario. Otras veces me dejaba mirar directamente durante corto tiempo. La instrumentista y encargada del material era la Señorita Josefina me decía $\mathrm{D}$. Luis que era la única manera de que durase un material tan delicado. Más adelante, me encargué siempre de mi propio material.

Cuando no había resecciones asistía al quirófano de cirugía abierta.

Por medio del Dr. Palencia adquirí media docena de aspiradores de Ellik en una pequeña fábrica de vidrios a las afueras de Madrid. Después de unos veinte días me despedí de $\mathrm{D}$. Luís que me deseó mucha suerte y a petición mía me dio la dirección en Londres donde podía hacerme con un resectoscopio como el suyo. Me entregó un certificado de asistencia "con gran interés el aprendizaje de la cirugía urológica endoscópica". Y un año después me dedicó su libro, "Para el Dr. Guitián en recuerdo de su estancia en el Hospital de la Beneficiencia, muy afectuosamente L.C.D. 1963.

En Ourense me incorporé al Hospital y me hice con un resectoscopio NESBIT (igual que el de D. Luís) y una decena de asas y lamparitas de repuesto. En el Hospital, próstata que extraía, próstata que resecaba a través de una vejiga artificial que construí yo. Me costó el fundido de varias asas, pero mereció la pena porque observaba mis progresos. Las bujías fundidas, tanto del resector como del cistoscopio, las enviaba a reparar a La Casa del Médico, en la madrileña calle de Atocha, frente a la Antigua Facultad de Medicina. Cuando creí que ya estaba en condiciones de aplicar esta técnica en pacientes, comencé con los que tenían próstatas pequeñas, con retención completa de orina y a medida que iba adquiriendo más práctica, iba aumentando el tamaño de próstatas y tumores vesicales y por lo tanto el número de pacientes resecados.

A principios de 1966, se celebró en la ciudad lusa de Oporto, un Congreso Internacional de Urología. Allí tuve la ocasión de saludar a D. Luís al que le conté mis progresos en la cirugía endoscópi$\mathrm{ca}$, por lo que me felicitó cordialmente. Los portugueses que suelen ser muy corteses y como asistíamos bastantes españoles (por aquella época los congresos eran muy reducidos) y los ponentes portugueses se esforzaban para hablar en castellano, cuando me tocó intervenir a mí, con un trabajo titulado "Cáncer de riñón de diagnóstico difícil. Cura por nefrectomía" (con los medios actuales no sería tan difícil), yo hice un preámbulo en gallego y más o menos dije que daba las gracias a los portugueses por esforzarse en hablar en castellano y que yo correspondería a esa cortesía expresándome en gallego, idioma común, ya que el primer rey portugués Afonso Enriques ( $S$. XI) era de Guimaraes, que estaba dentro del Reino de Galicia, que llegaba hasta Coimbra, y si algún día se unieran España y Portugal, formando lberia sería a través de Galicia. Recuerdo que D. Luís el primero en aplaudir y siguió todo el auditorio. La ovación fue tan grande y prolongada, que pasó el tiempo de exposición de mi trabajo, pero no se perdió nada.

Más adelante, con motivo de una de mis visitas a D. Luís, hablamos del tema histórico y lingüístico-cultural de Galicia y no estábamos de acuerdo. Le prometí que le enviaría un reciente discurso de un intelectual gallego, D. Ramón Piñeiro, con motivo de su entrada en la Real Academia Gallega de la Lengua, titulado "A lingoaxe e as lingoas". Me contestó con una extensa carta mecanografiada, que guardo -como toda su correspondencia- en la que decía que me agradecía el envío del libro, que a pesar de estar escrito en gallego lo leyó con el mayor gusto, pero que discrepaba en algunas cosas. Terminaba diciendo: "de todo esto tendré mucho gusto de volver a hablar con usted, pues son temas, no que me interesen, sino que me apasionan". "Se despide con un fuerte abrazo su gran amigo, L.C.D.".

En posteriores ocasiones que lo visité, procuré, no hablar del tema, porque él no lo comenzó, y yo no tenía ganas de posibles desavenencias con $D$. Luis.

Mis compañeros de hospital no se explicaban que pudiera operar dentro de la cavidad vesical sin abrir. Entonces se me ocurrió hacer una película en 1969 de $8 \mathrm{~mm}$. en color y muda, mediante unas maquetas de plastilina que hice yo. Me desplacé a Madrid con la película y el proyector para enseñársela a D. Luís en el Hospital de la Beneficencia. Reunió a sus colaboradores y al final de la proyección me felicitó y me aconsejó que la presentase en el próximo Congreso Nacional de Urología, que se celebraba en Santiago de Compostela en 1970. Alli la presenté y expliqué, con gran éxito, a pesar de que para la mayoría de los asistentes esta técnica era desconocida. Posteriormente fui invitado para proyectarla en la Casa de Salud de Valdecilla y después en al Real Academia de Medicina y Cirugía de Galicia, con sede en A Coruña. La guardé y 14 años después le concedieron una distinción honorífica por su carácter 
didáctico en el Curso Internacional de Cine Médico de Motril.

En 1970, con mi mediación fue invitado por la Academia Médico Quirúrgica de Ourense para dar una conferencia presentada por mí y el tema que expuso fue una novedad para la mayoría de los médicos asistentes "Técnica y resultados del tratamiento de las neoplasias vesicales". En la cena que se le ofreció me preguntó por mis adelantos en las resecciones y le contesté diciendo que estaba ilusionado, ya que la mayoría de los pacientes iban bien o bastante bien, como se podía observar en mi película (un paciente orinando). Al cabo de unos días me escribió una carta agradeciéndome todas mis atenciones y contándome que "después de mi estancia, en Orense, visité Santiago, Villagarcía, Pontevedra y estuve en el magnífico parador de Bayona".

A mediados de los años 70 la resección transuretral comenzó a ponerse de actualidad en España y se celebraban cursos y conferencias sobre esta técnica con expertos alemanes y de EE.UU. que exponían las grandes ventajas que tenía sobre la cirugía abierta, con proyección de diapositivas y dibujos, pero no de películas, ya que por aquella época aún no existían cámaras endoscópicas.

En 1975, D. Luís celebró un Curso de Urología en la Clínica de Nuestra Señora de la Concepción al que asistió el Dr. Iglesias, inventor de los tipos de resectores que llevan su nombre. Don Luís, habló de las ventajas de la resección y de que el mayor inconveniente era la hemólisis, que podía ser grave por lo que era muy importante que el paciente estuviera bien relajado mediante una correcta anestesia (que él solía hacerla raquídea) que hacía que la capacidad vesical fuese mayor y la presión del líquido de lavado menor y así se evitaría en gran parte su paso al torrente circulatorio; que él empleaba siempre agua esterilizada ya que la visión era mejor y por lo tanto el tiempo de intervención se acortaba (no debía de durar más de $60^{\prime}$ ) y en solo contados casos vertía en el agua de lavado, hacia el final de la intervención Manitol. Más adelante pude comprobar que solo lo ponía en vía venosa.

En 1980 le dije a $D$. Luis que tenía pensado hacer un viaje por la Baviera alemana, y visitar Munich (München). Me entregó una carta de presentación escrita en alemán (idioma que dominaba), para el prof. Mavermayer. Tuve la mala suerte de que en aquellos días se encontraba de viaje, pero fui recibido cordialmente por uno de sus ayudantes que me enseñó el quirófano en el momento en el que estaban haciendo una RTU; me sorprendió que usaran las mismas botas de goma color verde que utilizaba yo en mis intervenciones y tanta gracia hacía al que me veía (guardo la carta).

Me había obsequiado y dedicado en 1986 con su discurso en el acto de su recepción en la Real Academia Nacional de Medicina sobre "Origen y Desarrollo de los Cálculos Renales" y un ejemplar del discurso de inauguración que dio en dicha academia, titulado "Palabras sin imágenes", "Comentarios a la evolución de la Urología", y en un escrito aparte, decía que me agradecería que le enviase los pequeños cálculos expulsados después de un cólico renal. Tenía guardado cuatro para enviárselos metidos en un pequeño sobre que se me extravió, cosa que sentí mucho, y así se lo comuniqué, y me contestó que no me preocupase porque ya tenía los suficientes, como yo suponía, ya que a $\mathrm{D}$. Luis nadie le negaba nada.

Con el paso de los años el nivel de vida fue mejorando, a medida que la ciencia avanzaba a pasos agigantados. Se perfeccionaron los métodos de diagnóstico y el material quirúrgico. La cirugía endoscópica era cada vez más aceptada, aunque seguía habiendo detractores. Adquirí un nuevo resectoscopio, con arco de ballesta, modelo Iglesias y una fuente de iluminación de luz fría, ambas ACMI. La diferencia del nuevo resectoscopio con el antiguo era abismal ya que tanto la luminosidad como el campo de visión eran mucho mejores así como el corte con un nuevo electrobisturí. Esto permitía operar más y mejor con el aumento porcentaje de las resecciones y así en 1986 publiqué en Archivos Españoles de Urología El trabajo titulado Resultado de 700 casos de Resección Trans Uretral (1965-85). D. Luís me dio su cordial felicitación después de leer el trabajo.

Más adelante con el empleo del trocar de Reuter, que facilitaba la resección, el número de intervenidos era de $90 \%$.

El servicio de Urología en el viejo hospital lo llevaba solamente yo y me ayudaban en las intervenciones abiertas dos jóvenes practicantes lasí se les llamaban) que ayudaban muy bien en la cirugía abierta, y en las R.T.U. las ATS (que en los años 60 solo eran monjas). En 1979, pasamos al nuevo Hospital Santa María Madre que después se llamó Santa María Nai. Poco tiempo después se incorporaría otro urólogo (Dr. Gutiérrez) que posteriormente sería Jefe de Sección. Tuve sucesivos médicos en prácticas y el último el Dr. Ramos obtuvo posteriormente el título de especialista de urología. Les sucedió lo mismo que a mí con respecto a $\mathrm{D}$. Luís ya que sólo tenía una óptica de enseñanza bastante deteriorada.

Con la llegada del vídeo me recomendó D. Luís que la película que había hecho con maquetas 
y que tenía medio olvidada, pero guardada, debía pasarla a formato VHS, y comentarla, cosa que hice y le entregué a $D$. Luís una copia. Más adelante, en 1992 fue editada por Video Archivos Españoles de Urología (vol. 4 -no 1) y presentada por el Dr. E. Pérez-Castro Ellendt. Es la primera película que se hizo en España sobre la técnica de la Cirugía Urológica Endoscópica y hay quien dice que si no es la primera, es una de las primeras del mundo, ya que en los años 60 no existían cámaras de cine para adaptar a las ópticas del resectoscopio.

Un día vino al Servicio de Urología del hospital un representante de una casa de material médico quirúrgico presentándonos como una novedad una cámara de filmación intravesical. La probamos en una resección a un prostático que tenía un adenoma bastante grande, pero la cámara era muy pesada (más de $2 \mathrm{Kg}$.) y durante la intervención tenía que aguantarla el representante con mis indicaciones de "adelante", "atrás". No nos quedamos con ella, pensando que, con los avances de la ciencia habría otras cámaras más pequeñas y ligeras. Como tenía dos filmaciones de la parte externa en la que se veían las maniobras que yo hacía durante la resección, los trozos resecados que caían en el embudo con el filtro, etc. hice un montaje con una filmación de una cistolitotomía previa, a la R.T.U. en un adenoma grande (Dr. Gutiérrez) y otra usando previamente el trocar de Reuter. Estas películas las monté en un video (V.H.S.) y una copia se la envié a $D$. Luís y con fecha del 4 de mayo de 1992, me dio las gracias en una carta manuscrita que poseo (Figura 1). Es la última carta que tengo de $\mathrm{D}$. Luís.

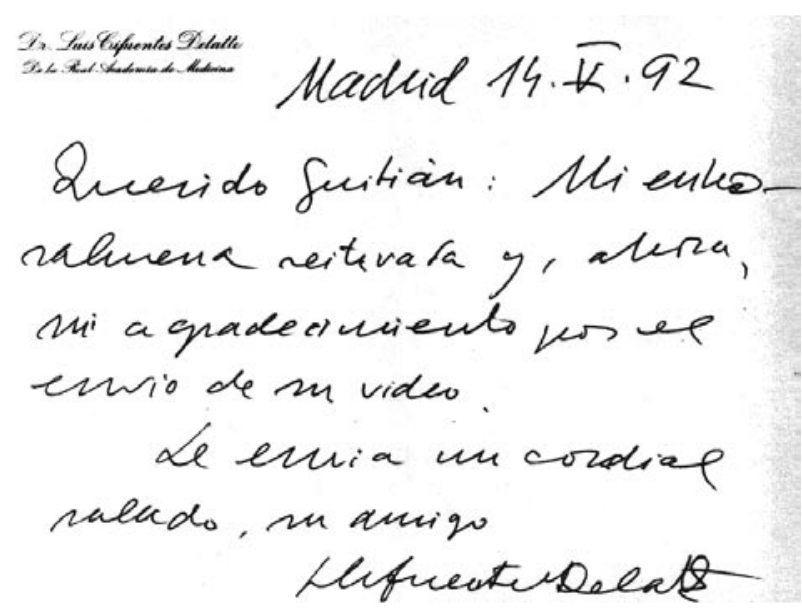

FIGURA 1. Carta de agradecimiento del Dr. Cifuentes (1992).
Más adelante el hospital adquirió una pequeña y ligera cámara. Hice mi última película sobre un tumor vesical de aspecto sólido, a un paciente que le habían hecho cirugía endoscópica varias veces fuera de Galicia. Le hice una R.T.U. (película) del que no pude seguir su curso porque fui jubilado del hospital a los 65 años, cuando estaba en la plenitud de mis facultades y en la "mejor forma". Posteriormente, le pregunté al Dr. Gutiérrez, y me dijo que le había hecho una cistoscopia a los tres meses y que estaba muy bien sin señales de tumor, más que una zona nacarada correspondiente a la resección y que al cabo de un año lo encontró en Santiago de Compostela donde fue a residir el paciente y le contó que lo revisara varias veces un urólogo de esa capital y que seguía muy bien, sin señales de tumor.

Seguí con mi consulta privada donde la mayoría de las intervenciones eran por R.T.U. Llegué a tener cerca de mil casos, la gran mayoría con éxito. Hace pocos años dejé la clínica privada.

Me enteré que $D$. Luis estaba enfermo, y fui a visitarlo, pero su esposa me dijo que era mejor que no lo viese, porque aparte de estar descansando no reconocía a nadie. Telefoneé con cierta frecuencia a su casa y me decían que seguía igual o peor.

No me enteré de su fallecimiento hasta días después de ocurrido y no pude asistir al sepelio como hubiera sido mi deseo. El periódico local no se hizo eco del triste acontecimiento, y no sé si la televisión lo haría.

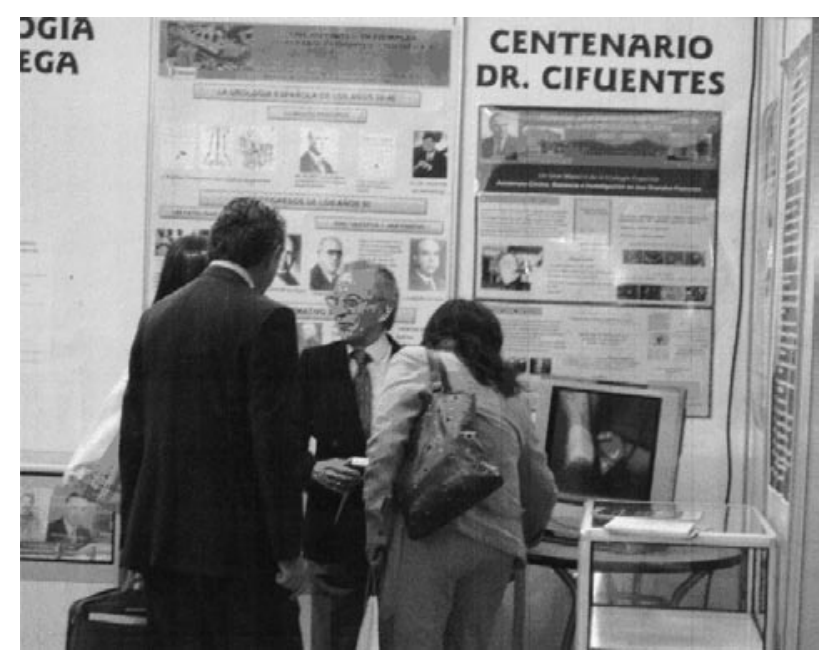

FIGURA 2. Stand dedicado al Dr. Cifuentes en el Congreso Nacional de Urología de la Coruña. 
Hace poco tiempo el Dr. Vela Navarrete me envió un número monográfico dedicado al Dr. Luis Cifuentes Delatte y editado por Actas Urológicas Españolas. Yo le había enviado anteriormente un DVD que recogía la primera película de resección transuretral (con maquetas), con otras filmadas en directo, sobre la R.T.U. de adenoma de próstata y otra sobre la R.T.U. de tumor vesical.

Por medio de un sobrino mío, archivero bibliotecario del Hospital Juan Canalejo de A Coruña, me enteré de que en el Congreso Nacional de Urología que se celebraba en A Coruña, había un stand dedicado al Dr. Cifuentes y en él se proyectaba continuamente mi último DVD sobre resecciones. Me desplacé al Palacio de Congresos de allí y el Dr. Vela Navarrete me enseñó el stand dedicado a D. Luis, con paneles sobre su vida y obra, en ella también había una vitrina de material urológico antiguo aportado por urólogos gallegos (entre ellos el profesor $\mathrm{Ci}$ madevila) y un proyector de DVD en el que exhibían continuamente mi DVD (Figura 2), que supongo fue el que le envié días antes al Dr. Vela Navarrete. Al frente del stand se encontraba un atento compañero que había conocido por teléfono, el Dr. Pérez Albacete, de Murcia. Me alegré de conocerlo personalmente y comprobar su amabilidad.

Termino diciendo que con el fallecimiento de D. Luis Cifuentes se perdió un hombre bueno, un científico e investigador y un gran escritor, pionero de la cirugía urológica en España y maestro de reseccionistas, entre los que yo me encuentro.

Adiós D. Luis, gracias por todo.

Su amigo, Carlos Guitián. 